\title{
Effects on growth and survival of loach (Misgurnus anguillicaudatus) larvae when co-fed on live and microparticle diets
}

\author{
Youji Wang ${ }^{1}$, Menghong $\mathrm{Hu}^{1}$, Weimin Wang' \& Ling $\mathrm{Cao}^{2}$ \\ ${ }^{1}$ College of Fishery, Key Laboratory of Agricultural Animal Genetics, Breeding and Reproduction of Ministry of Education, \\ Huazhong Agricultural University, Wuhan, China \\ ${ }^{2}$ School of Natural Resources and Environment, University of Michigan, Ann Arbor, MI, USA
}

Correspondence: $W$ Wang, College of Fishery, Key Laboratory of Agricultural Animal Genetics, Breeding and Reproduction of Ministry of Education, Huazhong Agricultural University,Wuhan, 430070 Hubei, China. E-mail: wangwm@mail.hzau.edu.cn

\begin{abstract}
The effectiveness of co-feeding loach (Misgurnus anguillicaudatus) larvae with live and microparticle diets on weaning performance was described here. Dry weight, total length, length and weight-specific growth rate (SGR) and survivals were monitored at $23-25^{\circ} \mathrm{C}$ from the 4 th day post hatching $(\mathrm{dph})$ in different diet regimes, which included: microparticle diets (A), live cladocerans (B), enriched cladocerans (C), half microparticle diets plus half live cladocerans (D) and half microparticle diets plus half enriched cladocerans (E). The SGR (L and W) were significantly lower in treatment $\mathrm{A}$ than in other treatments after completing metamorphosis (day 4-20, $P<0.05$ ). On $30 \mathrm{dph}$, dry weight $(\mathrm{mg})$ and total length $(\mathrm{mm})$ were significantly lower in treatment A than in other treatments $(P<0.05)$. There were no significant differences in growth in treatments B, C, D and E before $30 \mathrm{dph}$. However, when live feed was withdrawn from 31-60 dph, in metamorphosed fish, there were significant differences $(P<0.05)$ among the treatments in survival and growth. Metamorphosed fish in treatment $\mathrm{E}$ had higher survival than the fish in other treatments at the end of the experiment. The SGR (L and W) of weaned fish in treatments B and C were similar but lower than in treatments A, D and E respectively. However, dry weight and total length in treatment A were significantly lower than in treatments D and E. It is suggested that weaning of $M$. anguillicaudatus from early development would appear to be feasible and that larval co-feeding improves the growth and the survival.
\end{abstract}

Keywords: Misgurnus anguillicaudatus, fish larviculture, co-feeding, growth, survival, weaning

\section{Introduction}

Loach (Misgurnus anguillicaudatus) is an autochthonous fish of Asia (Chen 1976; Sterba 1983); there is a need for its high production, especially in Japan and Korea. The characteristics of this fish like omnivorous food habit, rapid growth, tolerance to high stocking density and utilization of atmosphere oxygen for respiration in oxygen-depleted water make loach a desirable cultivar of high market value. Stocking densities of loach fingerling with a total length of $2-3 \mathrm{~cm}$, in a paddy field, range from 20000 to 25000 fish per $1000 \mathrm{~m}^{2}$, with annual yields above $70 \mathrm{~kg}$, and rice production was higher than that without using loach (Xu \& Pan 2005). Moreover, the loach, for a long time, had been used as traditional Chinese medicine in folk remedies for treatment of hepatitis, osteomyelitis, carbuncles, inflammation and cancer, as well as for restoration to health in debilities caused by various pathogens and ageing (Qin, Huang \& Xu 2002); some active substances obtained from loach were found to be of high medical value (Kimura, Hama, Sumi, Asakawa, Rao, Horne, Li, Li \& Nakagawa 1994; Park, Lee, Park, Kim \& Kim 1997; Dong, Xu, Huang, Liu \& Zhou 2002; Zhang \& Huang 2005; Zhang \& Huang 2006).

Expanded and consistent requirements of loach production will therefore ultimately require development of all kinds of culture systems. In places like 
south China, loach culture such as rice-fish-farming ( $\mathrm{Lu} \mathrm{\&} \mathrm{Li} \mathrm{2006)} \mathrm{is} \mathrm{essential} \mathrm{because} \mathrm{the} \mathrm{wild} \mathrm{fry} \mathrm{is}$ scarce. Reliable, cultured fry production may soon become necessary even in south China, where environmental degradation has reduced wild fry yields (Beveridge, Phillips \& Macintosh 1997; Li 1999). Additionally, wild fry are only seasonally available, while artificial reproduction could ensure supply almost all year around.

Live feeds are important and essential for initial feeding of fish larvae (Holt 1993; Person Le Ruye, Alexandre, Thebaud \& Mugnier 1993) because they lead to increased feeding, stimulate the enzyme secretion and result in continuously good growth and survival. However, this increases the complexity, difficulty and the cost of juvenile fish production. Commercial diets used from initial feeding are of considerable technical and economic interest, as they reduce the dependency on live feeds and have a huge potential in meeting the requirements of food size and nutrition for the larvae (Lavens \& Sorgeloos 2000). Currently, there have been very few successful attempts to feed the larvae on inert diets from the onset of exogenous feeding in the hatchery (Cahu \& Zambonino Infante 1999). The poor performance of microdiets is related to the inadequate incorporation of nutrients because of poor ingestion, digestion and/ or assimilation. However, larval performance has markedly improved as larvae accept the inert diet in a shorter time if the inert diets are co-fed with live prey (Kolkovski, Tandler, Kissil \& Gertler 1993; Person Le Ruye et al. 1993; Kolkovski, Koven \& Tandler 1997; Kolkovski, Tandler \& Izquierdo 1997; Rosenlund, Stoss \& Talbot 1997).

Behavioural and physiological capacities determine whether fish larvae will eat manufactured diets. In a study of gilthead sea bream (Sparus aurata), Fernández-Díaz, Pascual and Yúfera (1994) found that larvae fed previously on live feeds prefer select live feed when co-fed with inert feed. This appears to be similar to the prior experience of feeding the snakehead larvae reported by Qin, Fast, Anda and Weidenbach (1997). This study implies that cofeeding will increase the acceptability of dry feed upon withdrawing the live feeds. The nutritional content of both live and manufactured diets, fish biology and husbandry are also of importance for the growth, survival and success of weaning (Bromley \& Howell 1983; Person Le Ruye et al. 1993). The important aspect of loach culture is larval rearing, provided enough high-quality larval fish are obtained before large-scale culture is developed. Appropriate first feeding diet is a major problem for successful larval loach rearing.

The present study aims to evaluate the effects that different treatments of live and microparticle diets had on the growth, survival and weaning of M. anguillicaudatus during the early phase of larval culture. This information is needed to determine the influence of larval co-feeding on weaning of M. anguillicaudatus.

\section{Materials and methods}

\section{Fish larvae}

The loach larvae used here came from hatcheryreared eggs of wild broodstock, kept for 2 weeks and spawned artificially. Eggs were incubated at $25-27{ }^{\circ} \mathrm{C}$ and $8.0-10.0 \mathrm{mg} \mathrm{L}^{-1}$ dissolved oxygen in incubation baskets held in a hatchery tank, with gentle aeration. After 24-30 h, larvae were hatched out. Three days later, when loach larvae could feed with a mouth width of $0.24 \pm 0.06 \mathrm{~mm}$, an initial length of $5.25 \pm$ $0.08 \mathrm{~mm}$ and an initial weight of $0.26 \pm 0.02 \mathrm{mg}$, a feeding trial was conducted.

\section{Experimental design}

After mouth opening [4 day post hatching (dph)] to $10 \mathrm{dph}$, the larvae were fed rotifers Brachionus calyciflorus cultured on beaker's yeast and microalgae (Chlorella sp.). The larvae were transferred to a set of 15 white fibreglass tanks of 100 L capacity. Each tank was stocked with 5000 larvae under the following environmental conditions: dissolved oxygen 8.0$10.0 \mathrm{mg} \mathrm{L}^{-1}$, water temperature $23-25^{\circ} \mathrm{C}$ and $\mathrm{pH}$ 7.0-7.3. Continuous water flow was maintained at a daily $20 \%$ exchange from 4 to $20 \mathrm{dph}$ and then gradually increased to achieve a 100\% daily exchange everyday by the end of the experiment. Light was supplied by two overhead fluorescent tubes set to produce a light intensity between 800 and $1000 \mathrm{~lx}$ at the water surface. Photoperiod initially set at 16:8 (h L:D) was increased to 20:4 at $35 \mathrm{dph}$, and then 24:0 by $45 \mathrm{dph}$ where it remained for the remainder of the trial.

Five different feeding regimes were supplied from 4 to $30 \mathrm{dph}$. These daily amounts increased with larval age (Table 1). Live cladocerans (Moina micrura Kurz) used in this study were enriched with product-50DE (Shandong Marine Fisheries Research Institute,Yantai, China), and the main composition was n-3 PUFA (particle diameter 3-6 $\mu \mathrm{m}$, Table 2). The enrichment 
emulsion was prepared by mixing $50 \mathrm{~mL}$ of $50 \mathrm{DE}$ with $500 \mathrm{~mL}$ water, shaken vigorously. After an 18$24 \mathrm{~h}$ hatching time, the emulsion was added to $500 \mathrm{~L}$ incubation water. Strong aeration was maintained using air stones and the temperature was maintained at $26^{\circ} \mathrm{C}$. After $6-8 \mathrm{~h}$, enriched cladocerans were harvested and fed to the larvae in treatments

Table 1 Daily amounts of microalgae $\left(10^{6}\right.$ cells $\left.\mathrm{mL}^{-1}\right)$, rotifers (individual $\mathrm{mL}^{-1}$ ), cladocerans (individual $\mathrm{mL}^{-1}$ ) and dry feed ( $\mathrm{mg}$ dry weight $\mathrm{mL}^{-1}$ ) given to Misgurnus anguillicaudatus larvae under five different feeding regimes

\begin{tabular}{llcll}
\hline & & \multicolumn{3}{c}{ Larval age (days) } \\
\cline { 3 - 5 } Regime & Food & $\mathbf{4 - 1 2}$ & $\mathbf{1 3 - 2 0}$ & $\mathbf{2 1 - 3 0}$ \\
\hline A & Algae & 0.3 & - & - \\
& Rotifer & 10 & - & - \\
& Dry feed & 12 & 16 & 24 \\
B & Algae & 0.3 & - & - \\
& Rotifer & 10 & - & - \\
& Cladoceran & 10 & 12 & 18 \\
C & Algae & 0.3 & - & - \\
& Rotifer & 10 & - & - \\
& Enriched cladoceran & 10 & 12 & 18 \\
D & Algae & 0.3 & - & - \\
& Rotifer & 10 & - & - \\
& Dry feed & 6 & 8 & 12 \\
& Cladoceran & 5 & 6 & 9 \\
E & Algae & 0.3 & - & - \\
& Rotifer & 10 & - & - \\
& Dry feed & 6 & 8 & 12 \\
& Enriched cladoceran & 5 & 6 & 9 \\
\hline
\end{tabular}

C and E. Feeding with artificial feed was carried out three times a day, while rotifers and cladocerans were introduced once a day, after the last feeding of artificial feed [Coated Micro Pellet No. 2, particles $<0.3 \mathrm{~mm}$, from Sifude Com. (Qingdao, China)] for the given day; the ingredients and proximate composition of the experimental diets are shown in Table 2. All the treatments were carried out in triplicate. On $4 \mathrm{dph}$, larvae were offered diets along with rotifers. Feeding with rotifers was terminated on $12 \mathrm{dph}$.

Weaning commenced on day 31 and during the first 7 days both live and inert feeds were fed. The transition from the initial regime to only dry feed was performed progressively, with a $12.5 \%$ decrease in the cladoceran rations per day. The amount of dry feed was gradually increased from $40 \mathrm{mg} \mathrm{L}^{-1}$ (day 31) to $600 \mathrm{mg} \mathrm{L}^{-1}$ (day 60) (about $25 \%$ of body weight per day). From day 38 onwards, in all the feeding treatments, only dry feed were supplied (Coated Micro Pellet No. 3, particles 0.3-0.5 mm, from Sifude Com.); the ingredients and proximate composition of the experimental diets are shown in Table 2. Every morning, the excreta and dead larvae were removed before first feeding through careful siphoning.

\section{Sampling}

Samplings were performed at day 4, 12, 20 and then every 10 days. On each sampling day, 15 larvae from each tank were rinsed with distilled water and dried

Table 2 Fatty acid composition (\% of total fatty acids) of the experimental enrichment product and formulation and composition of the experimental microparticle diets

\begin{tabular}{|c|c|c|c|c|c|}
\hline \multirow{2}{*}{$\begin{array}{l}\text { Enrichment } \\
\text { Fatty acid }\end{array}$} & \multicolumn{5}{|c|}{ Microparticle diets } \\
\hline & & Ingredients (\%) & & Proximate composition & \\
\hline $14: 0$ & $\operatorname{Tr}$ & Fish meal* & 68.0 & Dry matter (dm, \%) & 92.2 \\
\hline $16: 0$ & $\operatorname{Tr}$ & Cod liver oil $\dagger$ & 3.0 & Crude protein (\% dm) & 57.6 \\
\hline $16: 1 n-7$ & $\operatorname{Tr}$ & Phosphatidylcholine $\ddagger$ & 2.5 & Crude fat $(\% \mathrm{dm})$ & 12.5 \\
\hline $18: 1 n-9$ & 5.1 & Vitamin mixture $\S$ & 2.0 & Ash (\% dm) & 10.2 \\
\hline $18: 3 n-3$ & ND & Vitamin C (25\%) & 1.0 & Gross energy $\left(\mathrm{kJ} \mathrm{g}^{-1} \mathrm{dm}\right)$ & 21.8 \\
\hline $20: 3 n-3$ & ND & Choline chloride (60\%) & 1.0 & & \\
\hline $20: 4 n-3$ & ND & Mineral mixture $\S$ & 2.0 & & \\
\hline $20: 5 n-3$ & 27.0 & Wheat meal* & 10.0 & & \\
\hline $22: 5 n-3$ & 5.3 & Wheat gluten* & 10.0 & & \\
\hline $22: 6 n-3$ & 51.0 & Carboxy-methyl-cellulose & 0.5 & & \\
\hline
\end{tabular}

*PIASA, La Paz, B.C.S., Mexico.

$\dagger$ Drogueria Cosmopolita, S.A.de C.V., Mexico.

†Sigma P9671.

§Malta Cleyton, Malta Texo de Mexico S.A. de C.V., Mexico.

- Sigma C5013 (St Louis, MO).

Tr, trace $(<0.1 \%)$. ND, not detected. 
at $70{ }^{\circ} \mathrm{C}$ to a constant weight. The individual dry weight was calculated using an electronic balance. Larvae $<10 \mathrm{~mm}$ TL were measured under a dissecting microscope $(\times 20)$ by a micrometre, while larger fish were directly measured on a measuring board.

\section{Data and statistical analysis}

The growth rate of larvae was determined using the length and weight-specific growth rate (SGR) equation respectively.

$$
\begin{aligned}
& \mathrm{SGR}=\left(\left[\ln \left(L_{t}\right)-\ln \left(L_{0}\right)\right] / t\right) \times 100 \\
& \mathrm{SGR}=\left(\left[\ln \left(W_{t}\right)-\ln \left(W_{0}\right)\right] / t\right) \times 100
\end{aligned}
$$

Survival $(\%)=$ number of survivors at the

$$
\begin{aligned}
& \text { end of the experiment/ } \\
& \text { (number of larvae at the start } \\
& \text { - number of larvae sampled) } \\
& \times 100 \%
\end{aligned}
$$

where $L_{t}$ is the final length of larvae at time $t, L_{0}$ is the initial length (Ricker 1979; Cowan \& Houde 1990), $W_{t}$ is the final weight of larvae at time $t, W_{0}$ is the initial weight (Hopkins 1992; Rosenlund et al. 1997; Chang, Liang, Wang, Chen, Zhang \& Liu 2006) and t is the period of time between $L_{t}\left(W_{t}\right)$ and $L_{0}\left(W_{0}\right)$ in days.

Data on growth parameters were statistically analysed using one-way analysis of variance (ANOVA). Before the analyses, the data were evaluated for normality using the Kolmogorov-Smirnov nonparametric test and the plot of residuals was analysed to ensure that assumptions of ANOVA were satisfied. Differences among treatments were considered to be significant at $P<0.05$, and Tukey's HSD post hoc multiple range tests were performed to determine which treatment was different from the other. The results are expressed as the means \pm SD of the data.

\section{Results}

\section{Growth of weight and total length}

Generally, there were same trends in the data, demonstrating an increased dry weight and total length gain over time for treatments $\mathrm{B}, \mathrm{C}, \mathrm{D}$ and $\mathrm{E}$ over treatment A (Figs 1-4, Tables 4 and 5). There were no significant differences $(P>0.05)$ between treatments $\mathrm{B}, \mathrm{C}, \mathrm{D}$ and $\mathrm{E}$ before $30 \mathrm{dph}$, while larvae in treatments B, C, D and E were significantly heavier and longer than larvae in treatment A (Figs 1 and 3,
Tables 4 and 5). At $60 \mathrm{dph}$, larvae in treatments D and $\mathrm{E}$ were significantly heavier and longer than in treatments $\mathrm{A}, \mathrm{B}$ and $\mathrm{C}$, and those in treatments $\mathrm{B}$ and $\mathrm{C}$ were significantly heavier than treatment $\mathrm{A}$ (Figs 2 and 4,Tables 4 and 5). At the end of the trial, the values in treatments $\mathrm{D}$ and $\mathrm{E}$ were $650.98 \pm$ 27.9 and $670.6 \pm 25.66 \mathrm{mg}$, respectively, compared with $305.95 \pm 21.48,370.36 \pm 25.84$ and $382.22 \pm$ $23.78 \mathrm{mg}$ for treatment $\mathrm{A}, \mathrm{B}$ and $\mathrm{C}$, and were $42.21 \pm 3.22$ and $43.78 \pm 3.18 \mathrm{~mm}$ compared with $29.88 \pm 3.6, \quad 35.02 .36 \pm 3.15$ and $35.18 \pm 3.42 \mathrm{~mm}$ for treatments A, B and C (Tables 4 and 5). However, there were no significant differences $(P>0.05)$ in

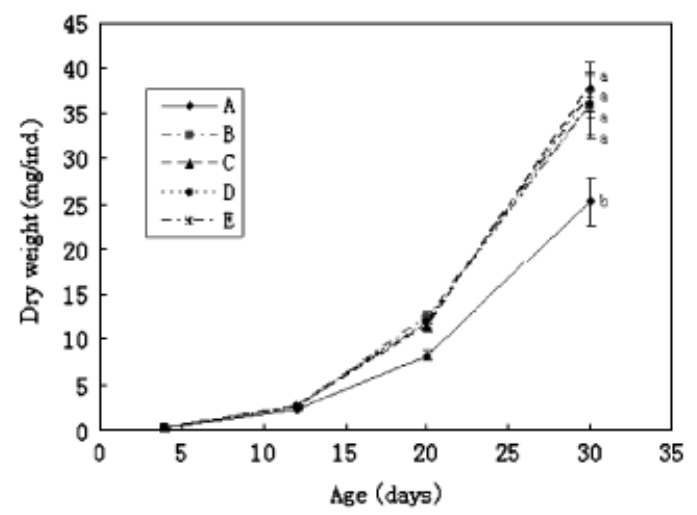

Figure 1 Changes in dry weight (mean \pm SD of three replicates) before weaning of Misgurnus anguillicaudatus larvae with different feeding regimes. SeeTable 1 for details of the feeding regimes. Points sharing a common lowercase letter are not significantly different $(P>0.05)$.

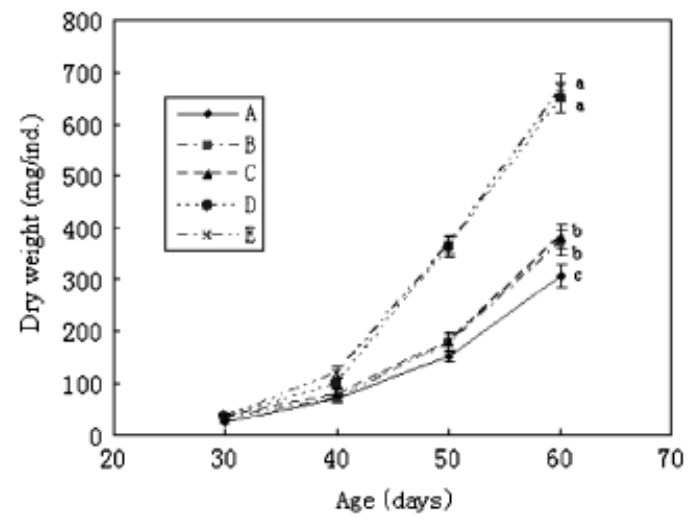

Figure 2 Changes in dry weight (mean \pm SD of three replicates) after weaning of Misgurnus anguillicaudatus larvae with different feeding regimes. SeeTable 1 for details of the feeding regimes until day 30. From day 30 to 60, all fish were fed dry feed. Points sharing a common lowercase letter are not significantly different $(P>0.05)$. 


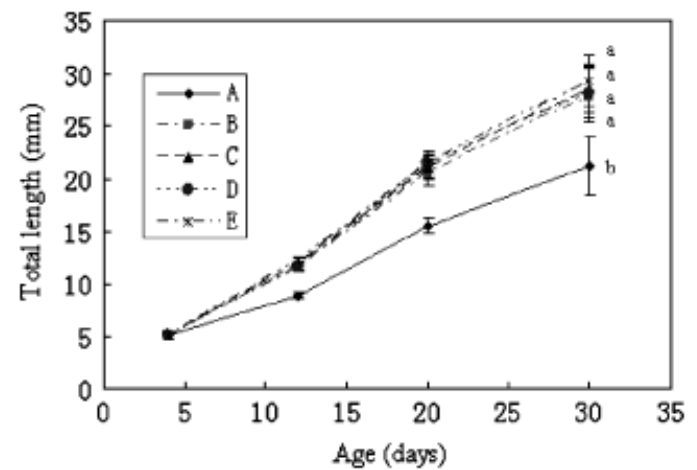

Figure 3 Changes in total length (mean \pm SD of three replicates) before weaning of Misgurnus anguillicaudatus larvae with different feeding regimes. See Table 1 for details of the feeding regimes. Points sharing a common lowercase letter are not significantly different $(P>0.05)$.

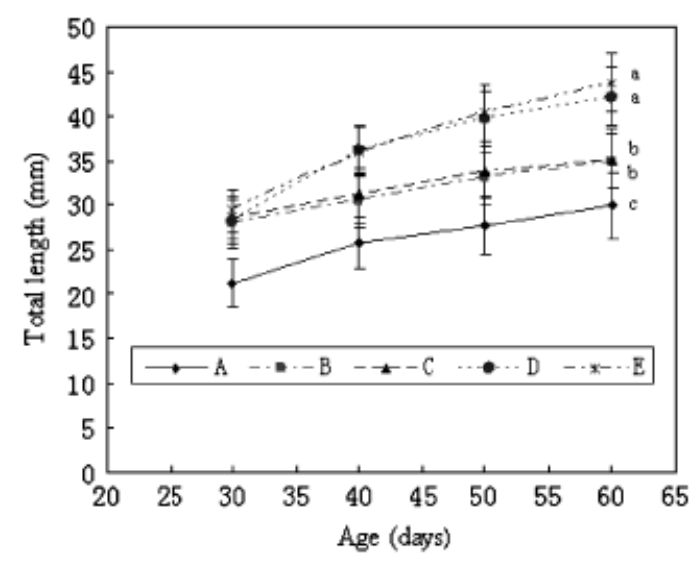

Figure 4 Changes in total length (mean \pm SD of three replicates) after weaning of Misgurnus anguillicaudatus larvae with different feeding regimes. See Table 1 for details of the feeding regimes until day 30. From day 30 to 60 , all fish were fed dry feed. Points sharing a common lowercase letter are not significantly different $(P>0.05)$. weights and lengths between larvae in treatments D and E.

\section{Weight and length - SGR}

The SGR was calculated to determine the growth performance during the experimental period and the results are shown in Table 3. There was a significant difference $(P<0.05)$ between the SGR $(W, L)$ of treatment A compared with the other treatments on metamorphosis (day 20) and days 20-30. However, from weaning to the end of the experiment, the SGR (3060 days) was significantly higher $(P<0.05)$ for fish in treatment $\mathrm{E}$, followed by treatment $\mathrm{D}$ and $\mathrm{A}>$ treatment $\mathrm{C}>$ treatment $\mathrm{B}$.

\section{Survival rate of loach larvae}

As expected, survival decreased as the period increased (Fig. 5). The survival rates in treatment $\mathrm{E}$ were significantly higher $(P<0.05)$ than fish in other treatments. Although significantly higher $(P<0.001)$ than fish in treatment $A$, there was no significant difference in the survival rate between treatments $C$ and $\mathrm{D}(\mathrm{P}>0.05)$. The percentage of survival in this period was significantly higher for fish in treatment $\mathrm{E}>\mathrm{D}>$ $\mathrm{C}>\mathrm{B}>\mathrm{A}$. More than $20 \%$ mortalities were observed in treatments $\mathrm{B}$ and $\mathrm{C}$ during the first 20 days when larvae were fed an inert diet only from $30 \mathrm{dph}$.

\section{Discussion}

The results indicate that larvae of M. anguillicaudatus had the capacity to complete metamorphosis when fed live and dry feed (co-feeding), achieving better growth and survival than larvae fed live feed or dry diets alone. Improved growth with live food, in com-

Table 3 Influence of diet on specific growth rate (\% SGR) (mean \pm SD) ${ }^{*}$ before and after weaning in Misgurnus anguillicaudatus

\begin{tabular}{|c|c|c|c|c|c|c|}
\hline \multirow[b]{2}{*}{ Feeding regime } & \multicolumn{3}{|l|}{ SGR (W, \%) } & \multicolumn{3}{|l|}{ SGR (L, \%) } \\
\hline & $4-20$ & $20-30$ & $30-60$ & $4-20$ & $20-30$ & $30-60$ \\
\hline$A$ & $21.57 \pm 1.7^{\mathrm{a}}$ & $9.26 \pm 0.9^{a}$ & $8.94 \pm 0.7^{b}$ & $6.79 \pm 0.5^{\mathrm{a}}$ & $2.51 \pm 0.3^{a}$ & $1.14 \pm 0.2^{\mathrm{a}}$ \\
\hline B & $23.65 \pm 2.2^{b}$ & $12.4 \pm 1.5^{b}$ & $6.78 \pm 1.1^{\mathrm{a}}$ & $8.53 \pm 0.7^{b}$ & $3.06 \pm 0.6^{b}$ & $0.72 \pm 0.1^{\mathrm{b}}$ \\
\hline C & $24.13 \pm 2.4^{b}$ & $11.96 \pm 1.4^{\mathrm{b}}$ & $6.86 \pm 0.6^{a}$ & $8.68 \pm 0.8^{\mathrm{b}}$ & $3.05 \pm 0.5^{\mathrm{b}}$ & $0.76 \pm 0.2^{b}$ \\
\hline D & $23.72 \pm 2.5^{\mathrm{b}}$ & $11.95 \pm 1.1^{\mathrm{b}}$ & $9.3 \pm 0.9^{b}$ & $8.78 \pm 0.5^{b}$ & $2.97 \pm 0.4^{\mathrm{b}}$ & $1.21 \pm 0.3^{\mathrm{a}}$ \\
\hline$E$ & $23.97 \pm 2.4^{\mathrm{b}}$ & $11.63 \pm 1.2^{\mathrm{b}}$ & $9.47 \pm 0.8^{b}$ & $8.81 \pm 0.6^{b}$ & $3.12 \pm 0.3^{b}$ & $1.34 \pm 0.2^{\mathrm{a}}$ \\
\hline
\end{tabular}

${ }^{*}$ Different superscript letters within a column indicate significant differences $(P<0.05)$. 
Table 4 Changes in dry weight (mg, mean \pm SD of three replicates) ${ }^{*}$ with different feeding regimes before and after weaning in Misgurnus anguillicaudatus

\begin{tabular}{|c|c|c|c|c|c|}
\hline \multirow[b]{2}{*}{ Age (days) } & \multicolumn{5}{|l|}{ Feeding regime } \\
\hline & $\mathbf{A}$ & B & C & D & $\mathbf{E}$ \\
\hline 4 & $0.26 \pm 0.02^{\mathrm{a}}$ & $0.26 \pm 0.02^{\mathrm{a}}$ & $0.26 \pm 0.02^{\mathrm{a}}$ & $0.26 \pm 0.02^{\mathrm{a}}$ & $0.26 \pm 0.02^{\mathrm{a}}$ \\
\hline 12 & $2.32 \pm 0.12^{b}$ & $2.50 \pm 0.15^{\mathrm{a}}$ & $2.55 \pm 0.13^{\mathrm{a}}$ & $2.63 \pm 0.16^{a}$ & $2.67 \pm 0.15^{\mathrm{a}}$ \\
\hline 20 & $8.20 \pm 0.52^{b}$ & $12.35 \pm 0.66^{\mathrm{a}}$ & $11.45 \pm 0.65^{\mathrm{a}}$ & $11.87 \pm 0.72^{\mathrm{a}}$ & $11.66 \pm 0.60^{\mathrm{a}}$ \\
\hline 30 & $25.28 \pm 2.68^{b}$ & $35.75 \pm 3.52^{\mathrm{a}}$ & $37.88 \pm 2.80^{\mathrm{a}}$ & $35.90 \pm 3.45^{\mathrm{a}}$ & $37.06 \pm 2.53^{a}$ \\
\hline 40 & $70.85 \pm 5.75^{c}$ & $72.50 \pm 8.40^{c}$ & $80.64 \pm 8.00^{c}$ & $100.90 \pm 10.10^{b}$ & $120.88 \pm 10.55^{a}$ \\
\hline 50 & $150.69 \pm 10.45^{c}$ & $177.77 \pm 15.47^{b}$ & $180.75 \pm 16.22^{b}$ & $361.74 \pm 19.54^{\mathrm{a}}$ & $365.47 \pm 18.75^{a}$ \\
\hline 60 & $305.95 \pm 21.48^{\mathrm{c}}$ & $370.36 \pm 25.84^{b}$ & $382.22 \pm 23.78^{b}$ & $650.98 \pm 27.90^{\mathrm{a}}$ & $670.60 \pm 25.66^{a}$ \\
\hline
\end{tabular}

${ }^{*}$ Different superscript letters within the same row indicate significant differences $(P<0.05)$.

Table 5 Changes in total length ( $\mathrm{mm}$, mean \pm SD of three replicates) ${ }^{*}$ with different feeding regimes before and after weaning in Misgurnus anguillicaudatus

\begin{tabular}{|c|c|c|c|c|c|}
\hline \multirow[b]{2}{*}{ Age (days) } & \multicolumn{5}{|l|}{ Feeding regime } \\
\hline & A & B & C & D & $\mathbf{E}$ \\
\hline 4 & $5.25 \pm 0.08^{\mathrm{a}}$ & $5.25 \pm 0.08^{a}$ & $5.25 \pm 0.08^{a}$ & $5.25 \pm 0.08^{a}$ & $5.25 \pm 0.08^{a}$ \\
\hline 12 & $8.94 \pm 0.25^{b}$ & $11.58 \pm 0.33^{\mathrm{a}}$ & $11.97 \pm 0.35^{a}$ & $11.60 \pm 0.40^{a}$ & $12.25 \pm 0.29^{\mathrm{a}}$ \\
\hline 20 & $15.55 \pm 0.84^{b}$ & $20.55 \pm 1.12^{\mathrm{a}}$ & $21.05 \pm 1.08^{a}$ & $21.38 \pm 1.21^{\mathrm{a}}$ & $21.46 \pm 0.95^{\mathrm{a}}$ \\
\hline 30 & $21.22 \pm 2.72^{b}$ & $27.90 \pm 2.64^{\mathrm{a}}$ & $28.26 \pm 2.32^{a}$ & $28.20 \pm 2.46^{a}$ & $29.31 \pm 2.35^{\mathrm{a}}$ \\
\hline 40 & $25.71 \pm 2.90^{\mathrm{c}}$ & $30.48 \pm 3.02^{b}$ & $31.11 \pm 3.20^{b}$ & $36.15 \pm 2.80^{a}$ & $35.98 \pm 2.75^{a}$ \\
\hline 50 & $27.60 \pm 3.18^{\mathrm{c}}$ & $33.06 \pm 2.95^{b}$ & $33.82 \pm 2.86^{b}$ & $39.77 \pm 3.05^{\mathrm{a}}$ & $40.37 \pm 3.10^{\mathrm{a}}$ \\
\hline 60 & $29.88 \pm 3.60^{c}$ & $35.02 \pm 3.15^{b}$ & $35.18 \pm 3.42^{b}$ & $42.21 \pm 3.22^{a}$ & $43.78 \pm 3.18^{\mathrm{a}}$ \\
\hline
\end{tabular}

* Different superscript letters within the same row indicate significant differences $(P<0.05)$.

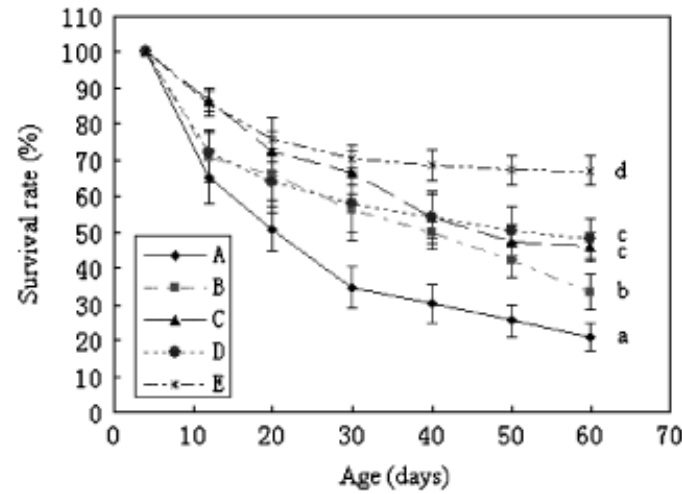

Figure 5 Mean survival of Misgurnus anguillicaudatus larvae in days 12, 20, 30, 40, 50 and 60 with different feeding regimes. See Table 1 for details of the feeding regimes until day 30. From days 30 to 60 , all fish were fed dry feed. Points sharing a common lowercase letter are not significantly different $(P>0.05)$.

bination with microdiets from first feeding or early development, has been reported for other species such as coregonids (Champigneuille 1988), sea bream and ayu (Kanazawa, Koshio \& Teshima 1989), Asian sea bass (Walford, Lim \& Lam 1991), Philippine freshwater catfish (Fermin \& Boliver 1991), snakehead (Qin et al.), milkfish (Borlongan, Marte \& Nocillado 2000), barramundi (Curnow, King, Partridge \& Kolkovski 2006) and Atlantic cod (Fletcher Jr, Roy, Davie,Taylor, Robertson \& Migaud 2007). It is suggested that larval fish utilize the exogenous enzymes of the live food as activators of zymogens in the gut, helping to complete the digestive process (Pedersen \& Hjelmeland 1988; Person Le Ruye et al. 1993). In this study, the colour of the stomach contents indicated the ingestion of dry feed when larvae were co-fed. It is suggested that loach larvae will eat dry feed in the presence of cladocerans and can utilize dry feed from an earlier developmental stage. However, it has been reported that some freshwater fish species were exclusively reared on artificial diets from the beginning of exogenous feeding (Charlon, Durante, Escaffre \& Bergot 1986; Appelbaum \& Van Damme 1988; Legendre, Kerdchuen, Corraze \& Bergot 1995; Carvalho, Araújo \& Santos 2006).

The digestive system of younger fish may lack special capacity for any particular diet, but as the fish grow, there may be physiological adaptations to suit 
particular diets. It was shown that the type of food consumed by larval fish affected the digestive physiology indefinitely (Segner, Rosch, Verreth \& Witt 1993), which implied that co-feeding would improve the digestive capacity of larval fish to suit dry diets. Barnabe and Guissi (1994) stated that when the feeding behaviour of the larvae was manipulated by suppressing the mobility of the live prey, larvae were no longer stimulated by the movement of the prey and would ingest immobilized live rotifers and microparticles alike. The present study indicated that the post-hatchlings of $M$. anguillicaudatus successfully weaned onto microdiets on an experimental scale. Enriched M. micrura plus dry feed was tested for the first time as a diet of M. anguillicaudatus, which interestingly proved to be highly useful in the experimental rearing of the post-hatchlings. The M. micrura have been used as a live feed for nursing carp (Cyprinus carpio) on a large scale owing to its higher economic value as reported by Jana and Chakrabarti (1993). Dry feed might have stimulated the digestive system of M. anguillicaudatus post-hatchlings in cofeeding treatments and increased the acceptance of formulated feed after $30 \mathrm{dph}$. It has an important implication for the commercial culture of this species, as the use of these formulated feed can drastically reduce material and labour costs, which in turn would increase the economic viability of a commercial operation.

Fluchter (1982) reported that different larval stages have specific nutritional requirements, while Bergot (1986) reported that artificial feeds change the relation that exists between the animal and its environment. Degani (1991) found that juvenile Trichogaster trichopterus fed with live feed grew faster than those fed on formulated feed because of the palatability, high consumption rate and chemical composition of the former; that was proved in this study. Similar observations have been reported by Hinshaw (1985) in yellow perch larvae. Several hypotheses (Hung, Tam, Cacot \& Lazard 1999; Hung, Tuan, Cacot \& Lazard 2002) have been proposed to explain the low effectiveness of the dry diet as the sole food supply for fish larvae. The poor growth rate and survival of M. anguillicaudatus larvae fed with dry feed could be due to low digestibility and incomplete nutriment of the feed as well as impaired feeding of the larvae. The deterioration of water quality and tank cleanliness due to the use of formulated feeds also probably affected the growth and survival rate of larvae in their early stage as reported by Abi-Ayad and Kestemont (1994).
In this study, only loach fed live feeds before weaning suffered higher mortality than did co-feeding fish. It is suggested that co-feeding preconditions the larvae to accept the microdiets when live feed is withdrawn, resulting in a shorter weaning period (Watanabe \& Kiron 1994; Rosenlund et al. 1997). This circumstance is similar to the findings of Canňavate and Fernández-Díaz (1999) in which the authors were unable to wean Solea senegalensis onto commercial dry feeds when the larvae had exclusively live prey. It appears that a transition period from live to inert feed of 7 days was not enough for the above species. The length of the weaning period had a significant effect on the growth. Longer weaning periods resulted in faster growth, which was also described in Rhombosolea tapirina by Hart and Purser (1996). Loach larvae fed a formulated diet had a high mortality rate only on $30 \mathrm{dph}$, which could be related to the poorly developed digestive enzyme system. Dabrowski (1982) reported that many small fish larvae do not have enzymes for digesting non-living diets. Dabrowski (1982) further suggested that initially, digestion in these fish larvae was carried out by enzymes present in their live prey.

Giri, Sahoo, Sahu, Sahu, Mohanty and Ayyappan (2003) observed higher survival of Wallago attu in larvae fed on live zooplanktons and under dry feed conditions as compared with live zooplanktons alone. This was also found in the present study. In the present study, a higher mean survival was observed for treatment $\mathrm{E}$ than in the other treatments. This could be due to the improved food intake by the post-hatchlings from live and artificial diets in treatment E. Another reason was that loach larvae ingested M. micrura enriched by 50 DE before weaning. Zhang, Chang, Zhang, Sun, Wang, Gong, Song and Li (1997) reported that $50 \mathrm{DE}$ was a perfect nutriment for zooplankton because of largely containing EPA and DHA. Hence, EPA and DHA are necessary fatty acids with respect to the growth and survival of larvae.

The results of the present study indicate that M. anguillicaudatus larvae actively feed on types of diets containing $M$. micrura. It shows that M. micrura plus other diets may serve as a potential diet for rearing post-hatchlings of $M$. anguillicaudatus. But it was not better that $M$. micrura alone was fed to loach than plus dry feed. This could be due to the compensatory and balanceable effects of dry feeds on growth. This research has paid attention to the fact that fish in treatments $\mathrm{B}$ and $\mathrm{C}$ need more time to adapt to nonmotile feeds after weaning, while fish in treatments $\mathrm{D}$ and $\mathrm{E}$ adapted more readily to formulated feed. 
Apparently, the longer the loach larvae are fed live food, the more difficult it is to wean them onto a formulated diet. Thus, a longer feeding period with live food simply postpones and increases the difficulty in weaning.

Although the experiment ended at day 60, a prolonged rearing period was needed to detect nutritional problems and observe the remote effect of co-feeding on weaning in the future. Based on our results, we believe that loach can successfully wean to formulated feeds using the following approach: feed larval loach with enriched cladocerans supplemented with formulated feed; after 30 days, gradually eliminate the live food over 7-10 days; then switch completely to formulated feed.

\section{Conclusions}

Our results indicate the reliability of the protocols for larval M. anguillicaudatus rearing at the experimental level by co-feeding with live and microparticle diets. This reduces the dependence on live foods, makes weaning easy and would imply a hatchery cost reduction in total live feeds' requirement and tank facilities. This study will help aquaculturists and researchers in improving loach larvae survival rate as well as help advance the commercial aquaculture of this species. The potential areas for further investigation to facilitate progress towards conservation and aquaculture of this species are the optimization of stocking density, nutritional composition of dry feed, feeding level and scaling up of the rearing protocols and genetic improvement.

\section{Acknowledgments}

This research was funded by 'National Key Technology R\&D Program in Eleventh-Five-Year Plan' titled as 'High quality and high efficiency freshwater aquaculture technology research program' (the accession number: 2006BAD03B07) and 'The integrated demonstration of safe fishery production' (the accession number: 2006BAK02A22). This research is also part of the AquaFish-ACRSP (Aquaculture Collaborative Research Support Program), supported by the US Agency for International Development (USAID).

\section{References}

Abi-Ayad A. \& Kestemont P. (1994) Comparison of the nutritional status of goldfish (Carassius auratus) larvae fed with live, mixed or dry diet. Aquaculture 128, 163-176.
Appelbaum S. \& Van Damme P. (1988) The feasibility of using exclusively artificial dry feed for the rearing of Israeli Clarias gariepinus (Burchell, 1822) larvae and fry. Journal of Applied Ichthyology 4, 105-110.

Barnabe G. \& Guissi A. (1994) Adaptation of the feeding behavior of larvae of the sea bass Dicentrarchus labrax (L.) to an alternating live food/compound-food feeding regime. Aquaculture and Fisheries Management 25, 537-546.

Bergot P. (1986) Elevage larvaire de la carpe commune (C. carpio): alimentation artificielle. In: Aquaculture of $\mathrm{Cy}$ prinids (ed. by R. Billard \& J. Marcel), pp. 227-234. INRA, Paris, France.

Beveridge M.C.M., Phillips M.J. \& Macintosh D.J. (1997) Aquaculture and the environment: the supply of and demand for environmental goods and services by Asian aquaculture and the implications for sustainability. Aquaculture Research 28, 797-807.

Borlongan I.G., Marte C.L. \& Nocillado J.N. (2000) Development of larval diets for milkfish (Chanos chanos). Journal of Applied Ichthyology 16, 68-72.

Bromley P.J. \& Howell B.R. (1983) Factors influencing the survival and growth of turbot larvae, Scophthalmus maximum $L$., during the change from live to compound feeds. Aquaculture 31, 31-40.

Cahu C. \& Zambonino Infante J. (1999) Substitution of live food by formulated diets in marine fish larvae. Aquaculture 200, 161-180.

Canňavate J.P. \& Fernández-Díaz C. (1999) Influence of cofeeding larvae with live and inert diets on weaning the sole Solea senegalensis onto commercial dry feeds. Aquaculture 174, 255-263.

Carvalho A.P., Araújo L. \& Santos M.M. (2006) Rearing zebrafish (Danio rerio) larvae without live food: evaluation of commercial, practical and purified starter diet on larval performance. Aquaculture Research 37, 1107-1111.

Champigneuille A. (1988) The first experiment in mass-rearing coregonid larvae in tanks with dry food. Aquaculture 74, 249-261.

Chang Q., Liang M.Q., Wang J.L., Chen S.Q., Zhang X.M. \& Liu X.D. (2006) Influence of larval co-feeding with live and inert diets on weaning the tongue sole Cynoglossus semilaevis. Aquaculture Nutrition 12, 135-139.

Charlon N., Durante H., Escaffre A.M. \& Bergot P. (1986) Alimentation artificielle des larves de carpe (Cyprinus carpio L.). Aquaculture 54, 83-88.

Chen T.P. (1976) Aquaculture Practices in Taiwan. Page Bros (Norwich), London, UK. pp. 155-156.

Cowan J.H. \& Houde E.D. (1990) Growth and survival of bay anchovy Anchoa mitchilli in mesocosm enclosures. Marine Ecology Progress Series 68, 47-57.

Curnow J., King J., Partridge G. \& Kolkovski S. (2006) Effects of two commercial microdiets on growth and survival of barramundi (Lates calcarifer Bloch) larvae within various early weaning protocols. Aquaculture Nutrition 12, 247-255. 
Dabrowski K. (1982) Proteolytic enzyme activity decline in starving fish alevins and larvae. Environmental Biology of Fishes 7, 73-76.

Degani G. (1991) The effect of diet, population density and temperature on growth of larvae and juvenile Trichogaster trichopterus (Bloch and Schneider 1901). Journal of Aquaculture in the Tropics 6, 135-141.

Dong X.Z., Xu H.B., Huang K.X., Liu Q. \& Zhou J. (2002) The preparation and characterization of an antimicrobial polypeptide from the loach, Misgurnus anguillicaudatus. Protein Expression and Purification 26, 235-242.

Fermin A.C. \& Boliver M.E.C. (1991) Larval rearing of the Philippine freshwater catfish, Clarias macrocephalus (Gunther) fed live zooplankton and artificial diet: a preliminary study. Israeli Journal of Aquaculture-Bamidgeh $\mathbf{4 3}$, 87-94.

Fernández-Díaz C., Pascual E. \& Yúfera M. (1994) Feeding behavior and prey size selection of gilthead seabream, Sparus aurata L., larvae fed on inert and live food. Marine Biology 118, 323-328.

Fletcher R.C. Jr, Roy W., Davie A., Taylor J., Robertson D. \& Migaud H. (2007) Evaluation of new microparticulate diets for early weaning of Atlantic cod (Gadus morhua): implications on larval performances and tank hygiene. Aquaculture 263, 35-51.

Fluchter J. (1982) Substance essential for metamorphosis of fish larvae extracted from Artemia. Aquaculture 27, $83-85$.

Giri S.S., Sahoo S.K., Sahu B.B., Sahu A.K., Mohanty S.N. \& Ayyappan S. (2003) Larval survival and growth in Wallago attu (Bloch and Schneider): effects of light, photoperiod and feeding regimes. Aquaculture 213, 151-161.

Hart P.R. \& Purser G.J. (1996) Weaning of hatchery-reared greenback flounder (Rhombosolea tapirina Günther) from live to artificial diets: effects of age and duration of the changeover period. Aquaculture 145, 171-181.

Hinshaw J.M. (1985) Effect of illumination and prey contrast on survival and growth of larval yellow perch Percaflavescens. Transactions of the American Fisheries Society 114, 540-545.

Holt G.J. (1993) Feeding larval red drum on microparticulate diets in a closed recirculating water system. Journal of The World Aquaculture Society 24, 225-230.

Hopkins K.D. (1992) Reporting fish growth: a review of the basics. Journal of The World Aquaculture Society 23, 173-176.

Hung T.H., Tam B.M., Cacot P. \& Lazard J. (1999) Larval rearing of the Mekong catfish, Pangasius bocourti (Pangasiidae, Siluridae): substitution of Artemia nauplii with live and artificial feed. Aquatic Living Resource 12, 229-232.

Hung T.H., Tuan N.A.P., Cacot P. \& Lazard J. (2002) Larval rearing of the Asian catfish, Pangasius bocourti (Siluridae, Pangasiidae): alternative feeds and weaning time. Aquaculture 212, 115-127.
Jana B.B. \& Chakrabarti R. (1993) The effect of management protocols for juvenile carp (Cyprinus carpio) culture on life history responses of a zooplankton food source, Moina micrura (Kurz). Aquaculture 110, 285-300.

Kanazawa A., Koshio S. \& Teshima S. (1989) Growth and survival of larval red sea bream Pagrus major and Japanese flounder Paralichthys alivaceus fed microbound diets. Journal of The World Aquaculture Society 20, 31-37.

Kimura M., Hama Y., Sumi T., Asakawa M., Rao B.N.N., Horne A.P., Li S.C., Li Y.T. \& Nakagawa H. (1994) Characterization of a deaminated neuraminic acid-containing glycoprotein from the skin mucus of the loach, Misgurnus anguillicaudatus. Journal of Biological Chemistry 269, 32138-32143.

Kolkovski S., Tandler A., Kissil G. \& Gertler A. (1993) The effect of dietary exogenous digestive enzymes on ingestion, assimilation, growth and survival of gilthead seabream (Sparus aurata Sparidae. Linnaeus) larvae. Fish Physiology and Biochemistry 12, 203-209.

Kolkovski S., Koven W. \& Tandler A. (1997) The mode of action of Artemia in enhancing utilization of microdiet by gilthead seabream Sparus aurata larvae. Aquaculture 155, 193-205.

Kolkovski S., Tandler A. \& Izquierdo M.S. (1997) Effects of live food and dietary digestive enzymes on the efficiency of microdiets for seabass (Dicentrarchus labrax) larvae. Aquaculture 148, 313-322.

Lavens P. \& Sorgeloos P. (2000) The history, present status and prospects of Artemia cysts for aquaculture. Aquaculture 181, 397-403.

Legendre M., Kerdchuen N., Corraze G. \& Bergot P. (1995) Larval rearing of an African catfish Heterobranchus logifilis (Teleostei,Clariidae): effect of dietary lipids on growth, survival and fatty acid composition of fry. Aquatic Living Resource 8, 355-363.

Li K.M. (1999) Management and Restoration of Fish Communities in Lake Taihu, China. Fisheries Management and Ecology 6, 71-81.

Lu J.B. \& Li X. (2006) Review of rice-fish-farming systems in China-One of the Globally Important Ingenious Agricultural Heritage Systems (GIAHS). Aquaculture 260, 106-113.

Park C.B., Lee J.H., Park I.Y., Kim M.S. \& Kim S.C. (1997) A novel antimicrobial peptide from the loach Misgurnus anguillicaudatus. FEBS Letters 411, 173-178.

Pedersen B.H. \& Hjelmeland K. (1988) Fate of trypsin and assimilation efficiency in larval herring Clupea harengus following digestion of copepods. Marine Biology 97, 467-476.

Person Le Ruye J., Alexandre J.C., Thebaud L. \& Mugnier C. (1993) Marine fish larvae feeding: formulated diets or live prey? Journal of The World Aquaculture Society 24, 211-224.

Qin C.G., Huang K.X. \& Xu H.B. (2002) Protective effect of polysaccharides from the loach on the in vitro and in vivo 
peroxidative damage of hepatocyte. The Journal of Nutritional Biochemistry 13, 592-597.

Qin J.G., Fast A.W., Anda D.D. \& Weidenbach R.P. (1997) Growth and survival of larval snakehead (Channa striatus) fed different diets. Aquaculture 148, 105-113.

Ricker W.E. (1979) Growth rates and models. In: Bioenergetics and Growth. Fish Physiology, Vol. VIII (ed. by W.S. Hoar, D.J. Randall \& J.R. Brett), pp. 678-743. Academic Press, New York, NY, USA.

Rosenlund G., Stoss J. \& Talbot C. (1997) Co-feeding marine fish larvae with inert and live diets. Aquaculture $\mathbf{1 5 5}$, 183-191.

Segner H., Rosch R., Verreth J. \& Witt U. (1993) Larval nutritional physiology: studies with Clarias gariepinus, Coregonus lavaretus and Scophthalmus maximus. Journal of The World Aquaculture Society 24, 121-134.

Sterba G. (1983) The Aquarium Fish Encyclopedia. The MIT Press, Cambrige, MA, USA, 605pp.

Walford J., Lim T.M. \& Lam T.J. (1991) Replacing live foods with microencapsulated diets in the rearing of sea bass (Lates calcarifer) larvae: do they ingest and digest protein-membrane microcapsules? Aquaculture $\mathbf{9 2}$, 225-235.

Watanabe T. \& Kiron Y. (1994) Prospects in larval fish dietetics. Aquaculture 124, 216-223.

Xu Z.K. \& Pan J.L. (2005) Key, Difficulty and Examples of Nonpolluting Culturing Misgurnus Anguillicaudatus and Monopterus albus. Scientific and Technical Documents Press, Beijing, China (in Chinese).

Zhang C.X. \& Huang K.X. (2005) Characteristic immunostimulation by MAP, a polysaccharide isolated from the mucus of the loach, Misgurnus anguillicaudatus. Carbohydrate Polymers 59, 75-82.

Zhang C.X. \& Huang K.X. (2006) Mechanism of apoptosis induced by a polysaccharide, from the loach Misgurnus anguillicaudatus (MAP) in human hepatocellularcarcinoma cells. Toxicology and Applied Pharmacology 210, 236-245.

Zhang L.M., Chang J.B., Zhang X.Z., Sun Y Z.,Wang J.Y., Gong X.H., Song L.H. \& Li Y.F. (1997) Studies on rotifera DHA enrichment with 50 DE microencapsulated product. Journal of Fishery Sciences of China 4, 4-49. 